\title{
SOBRE UM POSSÍVEL DÉFICIT DEMOCRÁTICO NO MODELO COSMOPOLITA HABERMASIANO
}

On a possible democratic deficit in the habermasian cosmopolitan model

Acerca de un posible déficit democrático en el modelo cosmopolita habermasiano

Cristina Foroni Consani'

Universidade Federal do Paraná, Curitiba, PR, Brasil.

\section{Resumo}

Este artigo apresenta o modelo cosmopolita habermasiano e levanta questionamentos a respeito de um possível déficit democrático em sua teoria. Primeiramente, apresenta-se o diagnóstico de época elaborado por Habermas que o leva à defesa da constitucionalização do direito internacional. Em um segundo momento, apresenta-se o prognóstico, isto é, a proposta de Habermas para constitucionalização do direito internacional. Ao final, analisa-se em que medida o arcabouço institucional-democrático delineado por Habermas para uma ordem política internacional oferece respostas para os problemas por ele mesmo suscitados.

Palavras-chave: Habermas. Cosmopolitismo. Política internacional. Déficit democrático.

1 Doutora em Filosofia e Mestre em Direito pela Universidade Federal de Santa Catarina. Professora Adjunta no Departamento de Filosofia da Universidade Federal do Paraná (UFPR), Curitiba, PR, Brasil. https://orcid.org/o000-0001-6072-9053. E-mail: crisforoni@yahoo.com.br 


\begin{abstract}
This paper presents the Habermasian cosmopolitan model and raises some questions about a possible democratic deficit in his theory. Firstly, the reasons that lead Habermas to defend the constitutionalization of international law are presented; secondly, Habermas's proposal for the constitutionalization of international law is presented; in the end, it analyzes the extent to which the institutional-democratic framework outlined by Habermas for an international political order offers answers to the problems he raised.
\end{abstract}

Keywords: Habermas. Cosmopolitanism. International politics. Democratic deficit.

\title{
Resumen
}

Este artículo presenta el modelo "Habermasiano" cosmopolitano y plantea interrogantes acerca de un posible déficit democrático en su teoría. En primer lugar, se expone el diagnóstico de la epoca elaborado por Habermas y lo que llévalo a la defensa de la constitucionalización del derecho internacional. Al final, analiza en qué medida el marco de la institucionalidad democrática descrita por Habermas para una orden política internacional proporciona respuestas a los problemas que planteados.

Palabras clave: Habermas. Cosmopolitismo. Política internacional. Déficit democrático.

\section{Introdução}

O processo de globalização e os problemas sociais por ele causados colocaram vários desafios políticos aos estados nacionais. As sociedades nacionais organizadas democraticamente são contrapostas às organizações internacionais concebidas em termos meramente econômicos. Diante disso, surge a necessidade de se buscar outras formas para o processo democrático e para a realização da justiça social além daquelas colocadas em prática dentro do Estado nacional. Jürgen Habermas encontra-se entre os filósofos contemporâneos da política que têm se debruçado sobre esses problemas.

O propósito deste artigo é apresentar o modelo cosmopolita habermasiano e levantar questionamentos a respeito de um possível déficit democrático em sua teoria. Isso será feito em três momentos: na primeira 
seção, será apresentado o diagnóstico de época elaborado por Habermas que o leva à defesa da constitucionalização do direito internacional; na segunda seção, será apresentado o prognóstico, isto é, a proposta de Habermas para a constitucionalização do direito internacional; e a terceira e última seção, tem por objetivo analisar em que medida o arcabouço institucional-democrático delineado por Habermas para uma ordem política internacional oferece respostas para os problemas por ele mesmo suscitados e, também, se esse modelo não seria maculado por um déficit democrático.

\section{Diagnóstico: os limites da política e da justiça nacional e o desenvolvimento de uma ordem internacional}

O diagnóstico de época de Habermas a respeito da constelação pós-nacional foi formulado no final dos anos 1990 e início dos anos 2000 e sofreu poucas alterações em seus textos mais recentes. Por um lado, ele analisa as transformações da economia e da política na era da globalização e, por outro, interpreta a evolução normativa da sociedade mundial apontando para as possibilidades de aprimoramento jurídico e moral na arena global. Partindo dessas considerações, três aspectos do diagnóstico de época feito por Habermas em sua defesa de um projeto de direito e de política cosmopolita requerem atenção, são eles: i) os problemas que afetam a soberania e a política no âmbito interno dos Estados; ii) a evolução do direito internacional; e iii) a ruptura com o processo de racionalização e civilizador em marcha no direito internacional promovida pela atuação norte-americana após os atentados de Onze de Setembro. Esses aspectos serão apresentados e analisados abaixo.

i) Ao revisitar o projeto cosmopolita kantiano, Habermas reconhece que os desafios colocados tanto pelas catástrofes do século $X X$ quanto pelos problemas sociais da globalização impulsionaram a retomada das ideias de uma justiça cosmopolita nos termos defendidos por Kant. A globalização, definida como um processo de expansão mundial do 
comércio e da produção, de mercados de bens e mercados financeiros, de modas, mídias e programas, de notícias e redes de comunicação, de fluxos de tráfego e movimentos de migração, dos riscos da alta tecnologia, dos danos ao meio ambiente e epidemias, do crime organizado e do terrorismo, tem como consequência deixar vulneráveis as sociedades em seu modo de organizar a política internacional, a política interna e a economia. No âmbito das relações entre Estados, ele avalia que, por um lado, a possibilidade de conflitos militares que poderiam levar a guerras nucleares entre as grandes potências mundiais parece improvável, por outro lado, aumentaram os conflitos locais com grande número de vítimas e migrantes. Ademais, a globalização impõe mudanças no funcionamento do direito público internacional no que diz respeito à soberania dos Estados e à nítida separação entre política interna e externa, haja vista que agentes privados passam a ter força econômica e política outrora só possível para Estados. Desse modo, ele ressalta que

[a]gentes não estatais como empresas transnacionais e bancos privados com influência internacional esvaziam a soberania dos Estados nacionais que eles mesmos atacam de um ponto de vista formal. Hoje em dia, cada uma das trinta maiores empresas do mundo em operação movimenta uma receita maior que o produto nacional bruto de noventa dos países representados na ONU, considerados individualmente².

Diante de tais transformações, Habermas chama a atenção para os limites impostos à política pela economia, haja vista que, enquanto a economia atua em âmbito global, a política continua a se organizar predominantemente de forma nacional, tornando-se, assim, incapaz de se impor à economia no que diz respeito a questões como a eliminação

2 HABERMAS, Jürgen. A ideia kantiana de paz perpétua - à distância de 200 anos. In: $A$ inclusão do outro: estudos de teoria política. Trad.: Georg Sperber e Paulo Astor Soethe. São Paulo: Loyola, 2002. p. 195. 
da desigualdade extrema, regulações trabalhistas e ambientais, contaminação atômica, entre outras.

ii) O segundo aspecto do diagnóstico de época habermasiano é a sua avaliação positiva da evolução do direito internacional a partir da segunda metade do século XX. Ele reconhece que desde o final da II Guerra Mundial ocorreu uma grande evolução do direito internacional, evolução essa, que se intensificou após o fim da guerra fria com o fortalecimento de instituições supranacionais (tais como as Nações Unidas e a União Europeia), a juridificação dos direitos humanos na Declaração Universal e a crescente importância de organizações transnacionais como as Organizações Mundiais do Comércio, da Saúde, do Trabalho e o G8. Essas mudanças, segundo Habermas, apontam para a criação de meios de governança global.

Habermas obviamente não é ingênuo a respeito das limitações dessas organizações e da própria atuação da ONU, por vezes omissa ${ }^{3}$ e em outras restrita em razão de sua estrutura organizacional e orçamentária. ${ }^{4}$ Contudo, ele assinala algumas inovações importantes que foram introduzidas pela Carta da ONU e pela Declaração Universal dos Direitos Humanos, as quais mostram que o direito internacional não é mais apenas um direito de Estados. São elas:

a) a admissão dos cidadãos individuais como sujeitos do direito internacional - o preâmbulo e o $\operatorname{art.} 1^{\circ} \mathrm{da}$ Carta da ONU, assim como a Declaração Universal dos Direitos Humanos atribuíram caráter normativo aos direitos humanos e passaram a admitir

\footnotetext{
3 Sobre a omissão da ONU Habermas narra o caso de Ruanda, no qual o Conselho de Segurança havia sido alertado sobre a iminência de um massacre e mesmo assim não autorizou uma intervenção, permitindo o massacre de 800 mil pessoas, a maioria delas pertencentes à minoria tutsi. Segundo Habermas, esse fato mostra o quanto a ONU ainda está amarrada aos interesses nacionais em detrimento das obrigações globais da comunidade internacional. Cf. HABERMAS, Jürgen. O projeto kantiano e o Ocidente dividido. In: O Ocidente dividido: Pequenos escritos políticos X. Trad.: Bianca Tavolari. São Paulo: Unesp, 2011. p. 237-238.

4 Sobre o orçamento da ONU, Habermas ressalta que é algo em torno de $4 \%$ do orçamento anual da cidade de Nova York. Cf. HABERMAS, Jürgen. O projeto kantiano e o Ocidente dividido. In: O Ocidente dividido: Pequenos escritos políticos $X$. Trad.: Bianca Tavolari. São Paulo: Unesp, 2011. p. 241, nota 93.
} 
que uma reclamação individual possa ser feita também por indivíduos e não apenas por Estados';

b) centralização do poder punitivo no Conselho de Segurança da ONU - estabelece-se a proibição fundamental à violência, que não pode ser invalidada por tratados internacionais; no caso de violação de regras, a ONU pode usar violência militar na função de polícia (nos termos do artigo 42 da Carta da ONU, o Conselho de Segurança pode ele próprio determinar as medidas que entender necessárias para cumprir este objetivo e o artigo 43 autoriza o Conselho de Segurança a empregar, sob seu comando, as forças armadas e apoio logístico que os Estados-Membros devem colocar à disposição). Segundo Habermas, a criação desse Alto Comando do Conselho de Segurança com poder de decisão e de implementação dessa decisão teria a finalidade de fomentar o hábito e a consciência entre os participantes para agir como membros de uma comunidade de Estados. Apesar da previsão legal, isso não foi de fato implementado e o Conselho de Segurança tem permitido que os Estados-Membros mais potentes implementem as sanções por ele adotadas. Habermas ainda ressalta que o poder sancionador do Conselho de Segurança da ONU também se estende à criação de tribunais internacionais, os quais processam crimes de guerra, a preparação para a guerra, genocídios e crimes contra a humanidade, além de processarem e julgarem membros de governos, servidores públicos e voluntários por atos cometidos a serviço de um regime criminoso ${ }^{6}$;

c) orientação para a inclusão - a ONU abre-se para a adesão de qualquer Estado que se obrigar a cumprir os fundamentos

Cf. HABERMAS, 2011, op. cit., p. 224-225.

Cf. HABERMAS, 2011, op. cit., p. 226-228. 
da Carta e das declarações de direitos humanos e não apenas para Estados configurados como democracias liberais, isto é, abre-se inclusive para regimes despóticos e criminosos. Por um lado, o preço a pagar é a contradição entre os princípios declarados da organização mundial e os padrões de direitos humanos de fato praticados. Entretanto, por outro lado, a estrutura inclusiva preenche uma condição necessária à demanda da comunidade internacional de transformar conflitos entre Estados em conflitos internos, de modo que os conflitos entre Estados seriam resolvidos por meios civilizados (os meios jurídicos utilizados dentro dos tribunais internacionais). Nesse sentido, a tolerância com as contradições entre princípios e práticas abriria um diálogo entre países do Ocidente e do Oriente, com maior sensibilidade para as diferenças culturais, étnicas e religiosas 7 .

iii) O terceiro aspecto do diagnóstico de época de Habermas é a identificação da interrupção da marcha racionalizadora e civilizatória da juridificação do direito internacional. Em seu entendimento, essa ruptura foi causada pela política recente do governo norte-americano que, após os atentados de 11 de setembro, passou a ignorar o direito internacional e a agir de acordo com suas próprias concepções do certo e do errado.

Habermas considera que o papel dos EUA na internacionalização do direito tem sido ambíguo. Por um lado, após a ll Guerra mundial, e também após a Guerra Fria, o governo norte-americano desenvolveu um ativismo considerável no campo do direito internacional (por exemplo, a criação da Organização Mundial do Comércio; a proteção à propriedade intelectual, a Convenção sobre Minas Terrestres e Armas Químicas, a ampliação do Tratado de Não proliferação de Armas Nucleares, Estatuto do Tribunal

Cf. HABERMAS, 2011, op, cit., p. 229-231. 
Penal Internacional). Por outro lado, o governo norte-americano não ratificou ou recusou vários tratados (por exemplo, aqueles que tratam do controle de armamentos, de direitos humanos, dos julgamentos de crimes internacionais e de proteção ao meio ambiente) ${ }^{8}$. Contudo, o que fez Habermas considerar a ocorrência de uma divisão no Ocidente foi a atuação dos EUA após os atentados de 11 de setembro, sobrepondo ao processo de juridificação em curso uma espécie de moralização ou eticização no âmbito das relações internacionais. Segundo Habermas,

a ONU [...] possui uma verdadeira Constituição que estipula procedimentos por meio dos quais violações a regras internacionais podem ser constadas e punidas. Desde então não existem mais guerras justas ou injustas, mas só guerras legais ou ilegais, ou seja, guerras legítimas e ilegítimas do ponto de vista do direito das gentes. É preciso relembrar esse enorme impulso da evolução jurídica para reconhecer a ruptura radical provocada pelo governo Bush - tanto com a doutrina da segurança nacional que deliberadamente ignora as condições juridicamente válidas para a utilização da força militar, como também do ultimato dado ao Conselho de Segurança: 'ou aprovar a política agressiva dos Estados Unidos em relação ao Iraque ou afundar em sua própria insignificância. [...] Com expressões morais, o governo Bush engavetou o projeto kantiano de juridificação das relações internacionais que tem mais de 220 anos $^{9}$.

Desse modo, Habermas (2011) aponta, no âmbito da política internacional, para uma contraposição entre o "direito" e "moral" - moral aqui compreendida como os valores éticos e convicções morais próprios dos norte-americanos (considere-se, por exemplo, a noção bastante difundida

8 Cf. HABERMAS, 2011, op. cit., p. 249-251.

9 HABERMAS, Jürgen. Uma entrevista sobre guerra e paz. In: O Ocidente dividido: Pequenos escritos políticos X. Trad. Bianca Tavolari. São Paulo: Unesp, 2011. p.146. 
da luta contra o mal na qual o significado de bem e mal é atribuído pelos próprios interessados). Desse modo, justificações normativas próprias de um povo são colocadas no lugar de procedimentos prescritos pelo direito internacional. O que se verifica é, segundo Habermas, um falso universalismo quando um Estado "substitui o direito positivo pela moral e pela ética em questões de justiça internacional"10.

O diagnóstico de época de Habermas mostra, portanto, que os Estados se encontram hodiernamente diante de dois modelos inadequados - uma juridificação insuficiente e uma moralização unilateral"1. Por um lado, a juridificação tem ocorrido por meio de procedimentos juridicamente estabelecidos por uma organização mundial inclusiva, mas impotente e que toma decisões seletivas. Por outro lado, as regras das relações internacionais passam a ser ditadas por uma ordem política unilateral de um hegemon que se apresenta como "bem-intencionado"12.

O projeto cosmopolita habermasiano intenta afastar-se de ambos os modelos. Ele aposta na constitucionalização do direito internacional em bases democráticas, o que implica na reformulação da organização mundial existente e no desenvolvimento do projeto de "uma política mundial sem governo mundial" (a ideia de Constituição sem Estado). Esse é o objeto de análise da próxima seção. ${ }^{13}$

\footnotetext{
10 HABERMAS, 2011, op. cit., 2011, p. 146.

$"$ Cf. COHEN, Jean L. The Constitutionalization of International Law. In: BRUNKHORST, Hauke; KREIDE, Regina; LAFONT, Cristina. The Habermas Handbook. New York: Columbia University Press, 2018. p. 144.

12 HABERMAS, Jürgen. O projeto kantiano e o Ocidente dividido. In: O Ocidente dividido: Pequenos escritos políticos $X$. Trad. Bianca Tavolari. São Paulo: Unesp, 2011. p.164.

13 Cf. HABERMAS, Jürgen. A Constelação Pós-Nacional: ensaios políticos. Trad.: Márcio SeligmannSilva. São Paulo: Littera Mundi, 2001. p. 131-132; HABERMAS, Jürgen. O projeto kantiano e o Ocidente dividido. In: O Ocidente dividido: Pequenos escritos políticos $X$. Trad. Bianca Tavolari. São Paulo: Unesp, 2011. p.188.
} 


\section{Prognóstico: democracia cosmopolita e constitucionalização do direito internacional}

O projeto de uma "política mundial sem governo mundial" está intimamente ligado à ideia segundo a qual uma república mundial ou estado de povos não são as únicas instituições que podem dar forma ao projeto cosmopolita kantiano. O receio de que um governo mundial possa ser despótico ou autoritário faz com que Habermas delineie um modelo cosmopolita que tem como ponto de partida estruturas e instituições já existentes (a ONU, os blocos regionais que têm na União Europeia seu melhor exemplo, as organizações internacionais como a do comércio ou do trabalho, entre outras, e também os Estados nacionais) e proponha uma constituição política da sociedade mundial descentralizada com um sistema de múltiplos níveis. Seriam eles: supranacional ou global, transnacional e, nacional.

O nível supranacional ou global pressupõe uma organização mundial reformada a fim de conseguir desempenhar de forma efetiva e não seletiva suas funções vitais, que seriam basicamente a manutenção da paz e a proteção aos direitos humanos, sem precisar assumir a forma estatal de uma república mundial'14. Na esteira dessa proposta, a ONU deveria ser reorganizada como uma comunidade politicamente constituída de Estadose cidadãos. Aqui, Habermas pensa em uma Assembleia Geral ou Parlamento Mundial constituído por cidadãos e por Estados, no qual deveriam ser levadas em consideração as pretensões dos cidadãos do mundo (direitos de igual tratamento e de igualdade distributiva) e dos cidadãos de cada Estado nacional'5. Deveria também haver uma reforma no Conselho de Segurança e nas Cortes de Justiça a fim de que estes conseguissem realizar efetiva e regularmente a garantia da paz e a proteção aos direitos humanos.

O nível transnacional é delineado a partir da ideia de blocos regionais, cujo melhor exemplo seria a União Europeia. Tratar-se-ia de um conjunto de

\footnotetext{
14 HABERMAS, 2011, op. cit., p. 189.

15 HABERMAS. Um ensaio sobre a Constituição da Europa. In: Sobre a Constituição da Europa: um ensaio. Trad. Denilson Luis Werle, Luiz Repa e Rúrion Melo. São Paulo: Unesp, 2012. p. 95.
} 
organizações intermediárias, no âmbito de conferências e sistemas de negociação permanentes, os grandes atores com capacidade de atuação global trabalhariam com os problemas difíceis de uma política interna mundial não só coordenadora, mas também configuradora, com especial atenção para os problemas da economia mundial e da ecologia. ${ }^{16}$ No modelo habermasiano, o nível transnacional seria o principal responsável pela implementação da justiça social, pois as regulações criadas neste nível teriam justamente a responsabilidade de impor limites aos mercados de trabalho e de bens e de crédito, de modo a proteger trabalhadores, meio ambiente e a sociedade em geral.

O nível nacional seria aquele constituído pelos Estados nacionais tais como existem contemporaneamente. Assumir-se-ia, contudo, que o direito de soberania seria restringido para observar as normas de garantia de paz e de proteção aos direitos humanos e também as diretrizes econômicas e sociais erigidas no âmbito transnacional que poderiam impulsionar a solidariedade além das fronteiras nacionais. Ademais, é no nível nacional que continuaria a ocorrer a formação da opinião e da vontade e a legitimação democrática em sentido forte. Segundo Habermas, "só no interior de Estados constitucionais democráticos existem providências jurídico-organizacionais para uma inclusão igualitária dos cidadãos no processo legislativo"17.

Nesse sistema de múltiplos níveis a legitimação democrática da juridificação não pode ser pensada, segundo Habermas, da mesma forma que ocorre dentro dos Estados. Ele delineia a legitimação democrática do direito internacional a partir de uma cadeia de legitimações, que vai do nível estatal até o nível global. No nível do Estado nacional, a criação do direito legítimo se estabelece nos moldes delineados por Habermas em sua teoria do discurso, isto é, o direito legítimo é o fruto de um processo de autodeterminação que só pode ocorrer sob condições de intersubjetividade compartilhada que o processo deve ter.

\footnotetext{
16 HABERMAS, Jürgen. O projeto kantiano e o Ocidente dividido. In: O Ocidente dividido: Pequenos escritos políticos X. Trad.: Bianca Tavolari. São Paulo: Unesp, 2011. p.189-19o.

17 HABERMAS, 2011, op. cit. p.197.
} 
No nível transnacional, assume-se a perspectiva de uma legitimação fraca ou indireta. Habermas sustenta que a juridificação democrática deve ocorrer no estilo da União Europeia, tendo em vista que os governos possuem a prerrogativa para a conclusão de tratados internacionais, os quais estão menos sujeitos à participação e à legitimação democrática do que a política interna controlada pelo Parlamento. No nível supranacional ou global, tem-se, segundo Habermas, uma necessidade reduzida de legitimação. Em seu entendimento,

[...] não podemos esperar dos cidadãos do mundo uma formação coletiva da vontade em sentido propriamente político. As eleições para o Parlamento mundial expressariam apenas o 'sim' e o 'não' moralmente fundamentados na aplicação supranacional de princípios e normas morais presumivelmente compartilhados" (grifos do autor) ${ }^{18}$.

A corrente de legitimação, diz Habermas, "se estenderia ininterruptamente desde os Estados nacionais, passando por regimes regionais como a União Europeia, até chegar ao âmbito da organização mundial"19. Tem-se, assim, um modelo de legitimação democrática em sentido forte - aquela que ocorre por meio dos procedimentos democráticos situados dentro do estado-nação, e uma legitimação democrática em sentido fraco - aquela da arena global. Ao mesmo tempo em que promove a redução das exigências de legitimação à medida que a produção legislativa afasta-se do nível nacional, em seu projeto de cosmopolitismo democrático Habermas repete um modelo delineado para a política interna dos Estados, qual seja, a distinção entre uma esfera pública em sentido forte - composta por instituições formais de tomada de decisões (como os parlamentos) e esfera

\footnotetext{
18 HABERMAS, Jürgen. Um ensaio sobre a Constituição da Europa. In: Sobre a Constituição da Europa: um ensaio. Trad. Denilson Luis Werle, Luiz Repa e Rúrion Melo. São Paulo: Unesp, 2012. p. 102. 19 HABERMAS, op. cit., 2012, p. 102.
} 
pública em sentido fraco (a sociedade civil global), a qual deve atuar para promover as metas política de proteção aos direitos e de solidariedade ${ }^{20}$.

A constitucionalização do direito internacional na perspectiva da "política mundial sem governo mundial" se estabelece, ao menos até a proposta apresentada em O Ocidente Dividido, de forma mais próxima ao modelo liberal (com foco na limitação recíproca do poder político e salvaguarda de direitos humanos) do que ao modelo republicano (cuja ênfase recai sobre o processo de cidadania ativa e autogoverno), tendo como referência a ideia de império da lei associada ao rule of law da tradição inglesa e ao Rechtstaat do direito alemão ${ }^{21}$. Essas características são ressaltadas por Habermas ao afirmar que a constitucionalização do direito internacional tem por objetivo regular

a atuação conjunta dos atores coletivos com o objetivo de limitar reciprocamente o poder, conduzem o jogo de poder pacificado de acordo com o procedimento para os trilhos da conformidade com os direitos humanos e deixam para os tribunais as tarefas de aplicação e de formação do direito sem um envolvimento direto com as demandas e controles democráticos. Então aqui 'a constitucionalização do direito internacional não tem o sentido republicano de uma juridificação das relações internacionais ${ }^{22}$.

Esse modelo seria o mais adequado a uma proposta de legitimação reduzida para a juridificação produzida nos âmbitos transnacional e global, haja visa que, segundo o filósofo alemão, procedimentos democráticos

20 Cf. BAYNES, Kenneth. Cosmopolitan Condition. In: BRUNKHORST, Hauke; KREIDE, Regina; LAFONT, Cristina. The Habermas Handbook. New York: Columbia University Press, 2018. p. 541-543. ${ }_{21}$ HABERMAS, Jürgen. O projeto kantiano e o Ocidente dividido. In: O Ocidente dividido: Pequenos escritos políticos X. Trad. Bianca Tavolari. São Paulo: Unesp, 2011. p.193.

22 HABERMAS, 2011, op. cit., p. 194. 
de legitimação exigem um tipo de solidariedade cidadã que dificilmente poderia ser estendido para além das fronteiras do Estado nacional. ${ }^{23}$

Desse modo, por um lado, Habermas vê o estabelecimento de um direito cosmopolita como uma resposta necessária aos efeitos desempoderadores da globalização. Por outro lado, ao reduzir o nível de exigência legitimadora e, por conseguinte, o nível de interferência dos indivíduos na política por meio da participação democrática, qual a garantia que se tem de que esses efeitos desempoderadores da globalização serão contidos? O modelo habermasiano de cosmopolitismo democrático tem recebido diversas críticas, as quais apontam limitações e problemas no âmbito da economia, da justiça social e da estrutura político-democrática.

No que diz respeito às questões econômicas, Wolfgang Streeck, talvez um dos mais duros críticos de Habermas nesse aspecto, tem enfatizado a cooptação da democracia pelo capitalismo e a necessidade de teorias da democracia levarem a sério questões de economia política. Crítico de modelos de democracia transnacional, ele considera que os estados nacionais ainda são as instituições políticas mais importantes da Europa e que, nos termos que a relação entre política e capital se estabeleceu dentro da União Europeia, quanto mais as instituições nacionais se abrirem para a interferência transnacional, mais elas sofrerão a imposição de um projeto avesso à democracia social almejada ${ }^{24}$.

Com relação às demandas de justiça social que poderiam ser contempladas a partir da constitucionalização do direito internacional, o projeto habermasiano tem sido considerado aquém do almejado para assegurar os direitos humanos e promover a justiça social, principalmente no que diz respeito a violações massivas de direitos humanos de origem econômica. Nesse sentido, Cristina Lafont, ao analisar o modelo cosmopolita habermasiano e sua estrutura de múltiplos níveis, ressalta que as

\footnotetext{
23 HABERMAS, 2011, op. cit., p. 193.

24 Cf. STREECK, Wolfgang. Small-State Nostalgia? The Currency Union, Germany, and Europe: A Reply to Jürgen Habermas. Constellations, v. 21, n. 2, 2014. p. 213-221.
} 
responsabilidades e as funções atribuídas para o âmbito global (assegurar a paz e proteger os direitos humanos) e para o âmbito transnacional (lidar com a denominada política doméstica global, na qual estão abarcadas questões econômicas, ambientais e de justiça social) criam um sistema ineficaz e cujo potencial protetivo é ainda inferior àquele já existente nos documentos jurídicos internacionais. ${ }^{25}$

Lafont critica principalmente o que ela denomina de "interpretação ultraminimalista dos deveres de justiça da comunidade internacional"26, 0 que implica a recusa da realização de redistribuição no âmbito global, haja vista que ao mencionar a proteção aos direitos humanos Habermas parece se referir apenas à proteção desses direitos em relação a ações dos Estados contra os cidadãos ou a ações de um grupo contra outro (crimes contra a humanidade, genocídios, extermínios em massa, por exemplo), mas não a omissões dos Estados em relação a seus cidadãos (como os casos de mortes por doenças curáveis ou ainda mortes por desnutrição ou por fome). ${ }^{27}$ Assim, por um lado, ela considera que a reforma proposta por Habermas no nível global é tão mínima que transforma as atribuições da ONU em algo inferior ao que já existe em termos da legislação internacional e das declarações de direitos. Por outro lado, a proposta tanto exonera as instituições que protegem os direitos humanos das imensas

\footnotetext{
${ }_{25}$ O principal ponto da crítica é que os direitos que Habermas considera responsabilidade da ONU proteger pela via da juridificação são mais restritivos do que aqueles que já se encontram protegidos nas declarações de direitos que surgiram desde a segunda metade do século XX, principalmente no que diz respeito aos direitos humanos cuja proteção e promoção estão atreladas à interferência política em questões econômicas e comerciais. Ela cita o exemplo do artigo 24 da Declaração Universal dos Direitos Humanos que reconhece o direito a férias remuneradas. Cf. LAFONT, Cristina. Alternative visions of a new global order: what should cosmopolitans hope for? Ethics \& Global Politics, v. 1, n. 1-2, 2008, p. 45.

26 LAFONT, 2008, op. cit., p. 47.

27 Aqui a autora traz o exemplo do conflito entre os direitos de propriedade intelectual de empresas que desenvolveram medicamentos para tratamento do vírus HIV, contrapondo-o ao direito à saúde das populações de países pobres. Ela traz dados empíricos de companhias farmacêuticas que acionaram a legislação internacional de proteção à propriedade intelectual e recorreram aos tribunais internacionais quando governos de países pobres começaram a produzir medicamentos genéricos para tratamento do vírus HIV. Cf. LAFONT, Cristina. Alternative visions of a new global order: what should cosmopolitans hope for? Ethics \& Global Politics, v. 1, n. 1-2, 2008, p. 49-50.
} 
tarefas da política global doméstica ou transnacional (a justiça social) quanto isenta a política global doméstica do dever de proteger os direitos humanos. A promoção da justiça social no âmbito transnacional não é um dever, mas uma meta política cujo conteúdo dependerá, em cada caso, das orientações ético-políticas dos principais global players envolvidos. ${ }^{28}$

Quanto às críticas formuladas à estrutura político-democrática, estas vão desde as dificuldades de se pensar em um projeto de Constituição sem Estado 29 à denúncia de um déficit democrático nas instituições globais e transnacionais, haja vista que, por um lado, o nível global de legitimação não é um processo de autogoverno positivo, mas um processo negativo de manutenção da paz e dos direitos humanos ${ }^{30}$; por outro lado, no nível transnacional, embora Habermas pense em instituições regionais, ele também reconhece a dificuldade de se estabelecer uma espécie de solidariedade cívica capaz de sustentar o nível de participação política mais intenso, como o que ocorre dentro dos Estados nacionais.

Desse modo, diante da aceitação de Habermas de uma espécie de legitimação do direito que vai se tornando menos exigente à medida que o direito vai se afastando do nível nacional, uma questão que pode ser colocada é se não haveria um déficit democrático no projeto cosmopolita habermasiano. Ou, ainda, em que medida essa legitimação em cadeia sem contestação democrática institucionalizada não criará um simulacro de instituições que atuam em nome da justiça global ao mesmo tempo em que continuam a operar na defesa de interesses meramente econômicos, crítica essa, aliás, que o próprio Habermas tem dirigido à União Europeia e ao Conselho Europeu, acusado de promover uma espécie de "federalismo executivo" que impõe os imperativos do mercado aos orçamentos

\footnotetext{
28 LAFONT, 2008, op. cit., p. 46-47.

29 Cf. SCHEUERMAN, William E. All Power to the (State-less?) General Assembly! Constellations, v. 15, n. 4, 2008, p. 485-492; SCHEUERMAN, William E. Global Governance without Global Government? Habermas on Postnational Democracy. Political Theory, v. 36 n. 1, 2008, p. 485-492. 30 Cf. ROELE, Isobel. The Vicious Circles of Habermas' Cosmopolitics. Law Critique, 2014, v. 25 , p. $199-229$.
} 
dos Estados ${ }^{31}$. Essas questões também são colocadas por Habermas, que em seus textos mais recentes sobre esse tema, tem defendido um aprofundamento do projeto político e o fortalecimento de uma democracia transnacional como meio se contrapor às imposições do mercado.

\section{Um possível déficit democrático no cosmopolitismo habermasiano}

Muitos dos textos de Habermas a respeito de um projeto de constituição para a Europa e do fortalecimento da legitimação democrática das políticas para a União Europeia podem ser lidos como tentativas de responder às críticas acima apresentadas. ${ }^{32}$ Assim, suas reflexões a respeito do futuro da União Europeia podem ser entendidas não apenas como uma tentativa de pensar o desenho institucional europeu, mas também como um exemplo de como poderia funcionar a democracia, o direito e a justiça social no nível transnacional.

Ao analisar a situação da União Europeia, Habermas considera que se pode observar uma racionalização do exercício do poder, da qual resultou uma melhora nas relações organizacionais graças à cooperação interestatal. Mas somente seria possível falar em "civilização" do exercício do poder se as organizações internacionais exercessem as suas competências com base não apenas em tratados internacionais (isto é, na forma do direito), mas também de acordo com o direito positivado democraticamente ${ }^{33}$. Segundo ele,

"sob a etiqueta inocente de governance, os regimes tecnocráticos se expandirão na medida que não se consegue explorar as fontes de uma legitimação democrática também para as

31 HABERMAS, Jürgen. Um ensaio sobre a Constituição da Europa. In: Sobre a Constituição da Europa: um ensaio. Trad. Denilson Luis Werle, Luiz Repa e Rúrion Melo. São Paulo: Unesp, 2012, p. 89.

${ }^{32}$ Nesse sentido, ver as obras mais recentes de Habermas sobre este tema: Sobre a Constituição da Europa e Na esteira da tecnocracia.

33 HABERMAS, Jürgen. Palavras-chave para uma teoria discursiva do direito e do Estado democrático de direito. In: Na esteira da tecnocracia. Trad.: Luiz Repa. São Paulo: Unesp, 2014, p. 110. 
autoridades supranacionais. É inadiável uma transnacionalização da democracia"34.

Habermas cita como exemplo de tecnocracia a Comunidade Monetária Europeia e as restrições que têm sido impostas à capacidade de ação dos Estados. Segundo ele, "a transformação do Estado dos impostos no Estado das dívidas forma hoje o pano de fundo de um círculo vicioso que consiste nos Estados resgatando bancos arruinados, e depois esses mesmos bancos, por seu turno, empurrando os Estados à ruína [...]"35.

A ordem democrática transnacional, contudo, deverá se organizar de modo distinto do que ocorre no Estado nacional. Trata-se de pensar em um desenho institucional baseado no conceito de soberania partilhada, o qual implica compreender como sujeitos ativos do poder soberano tanto os cidadãos quanto os Estados. Esse desenho institucional, contudo, não seria o de uma federação, na qual os estados membros figuram como poderes constituídos. Em uma democracia transnacional, os estados-membros devem figurar como poder constituinte e, por essa razão, manteriam competências mais fortes no interior da coletividade constituída. Habermas propõe que imaginemos uma convenção constitucional da qual fariam parte cidadãos europeus, por um lado, e Estados europeus, por outro, os quais decidiriam os contornos da União Política a ser constituída ${ }^{36}$.

No caso da União Europeia, ele pensa que três modificações seriam necessárias para que a União Política pudesse fazer frente à econômica no sentido de promover efeitos redistributivos transnacionais. Em primeiro lugar, ele considera ser necessária a tomada de uma decisão de transformar a Comunidade Monetária Europeia em uma União Política que se mantenha aberta ao ingresso de outros Estados-membros (Habermas

\footnotetext{
34 HABERMAS, 2014, op. cit., p. 112.

35 HABERMAS, 2014, op. cit., p. 185.

36 HABERMAS, 2014, op. cit., p. 112-115.
} 
pensa na possibilidade de uma nova fundação da União Europeia) ${ }^{37}$; em segundo lugar, essa refundação significaria, segundo Habermas, mais do que a transferência de direitos de soberania particulares. Implicaria o estabelecimento de uma política fiscal, orçamentária e econômica comum, e também uma política social coordenada. Seria preciso abrir mão da ideia de que os Estados são os senhores dos tratados.

Mas Habermas não quer pensar em uma federação ou confederação (uma espécie de Estados Unidos da Europa). Ele sugere que as competências de controle para uma comunidade monetária deveriam ser centralizadas no quadro de uma coletividade supraestatal, mas democrática. Por outro lado, os estados nacionais deveriam ser conservados, juntamente com a sua substância estatal (o monopólio da violência e administração) ${ }^{38}$; em terceiro lugar, seria preciso "destronar" o Conselho Europeu que se coloca acima do processo de legitimação e substituir o intergovernamentalismo pelo "método comunitário" (fortalecimento dos procedimentos democráticos de tomada de decisão).

Assim, o modelo de democracia transnacional por ele delineado com base na União Europeia deveria ter em suas bases o conceito de solidariedade. Nesses ensaios mais recentes, parece que Habermas modifica a sua forma de pensar a constitucionalização do direito internacional, ao menos no que diz respeito ao nível transnacional, assumindo aspectos de um modelo republicano que em textos anteriores havia sido recusado, como, por exemplo, a ênfase em uma espécie de solidariedade que extrapola o nível nacional.

Em sua definição, o conceito de solidariedade difere do conceito de justiça. Segundo ele, normas justas "são normas morais e jurídicas quando elas regulam práticas que residem no interesse simétrico de todos os concernidos"39 (como liberdades iguais ou igual respeito). O conceito de solidariedade, por sua vez, está relacionado ao de eticidade, aqui pensada

\footnotetext{
37 HABERMAS, 2014, op. cit., p. 130-131.

38 HABERMAS, 2014, op. cit., p. 132.

39 HABERMAS, 2014, op. cit., p. 141.
} 
no sentido de comportamento recíproco previsível ${ }^{40}$.Tais obrigações éticas possuem, segundo Habermas, três características: a) fundamentam pretensões supererrogatórias que vão além do que o destinatário é obrigado juridicamente ou moralmente. Nesse sentido, o cumprimento de uma obrigação ética não pode ser nem forçado (pelo direito) e nem categoricamente exigido (pela moral), mas depende "da previsibilidade do comportamento recíproco - e da confiança nessa reciprocidade ${ }^{\prime \prime 4}$; b) referem-se ao interesse comum, ao bem-estar e à integridade de uma forma de vida comum ${ }^{42}$; e c) pressupõem contextos de vida políticos organizados juridicamente e, nesse sentido, artificiais (não demandam a ideia de uma comunidade ligada por laços culturais ou tradicionais). ${ }^{43}$ Isso porque, segundo Habermas, "a 'solidariedade' (diferentemente da 'eticidade', não se refere ao contexto da vida existente, e sim a um contexto de vida certamente pressuposto, mas configurável politicamente." (grifos do autor) ${ }^{44}$

O conceito de solidariedade pode ser tomado como chave para pensar a democracia e a justiça transnacional. Ele tem uma estreita relação com a política e com o direito, haja vista que esses parecem ter que estabelecer os contornos dentro dos quais o ideal de "comportamento recíproco" pode tornar-se previsível. Um exemplo dado por Habermas é o caso da evasão fiscal:

No afeto contra esses aproveitadores se expressa, porém, a mesma expectativa de solidariedade desiludida que se manifesta no desprezo por todos os Depardieus que fazem evasão fiscal nesse mundo, que deslocam a sua residência, ou a sede de sua firma, para o exterior legalmente. Como é perceptível no desenvolvimento do Estado de bem-estar social, as expectativas de solidariedade podem se transformar em pretensões jurídicas. Hoje, ainda é uma questão de soli-

\footnotetext{
40 HABERMAS, 2014, op. cit., p. 142.

${ }^{41}$ HABERMAS, 2014, op. cit., p. 143.

42 HABERMAS, 2014, op. cit., p. 143.

43 HABERMAS, 2014, op. cit., p. 144.

44 HABERMAS, 2014, op. cit., p. 148.
} 
dariedade, e não de direito, saber com quanta desigualdade querem viver os cidadãos de uma nação próspera. Não é o Estado de direito que freia o aumento do número de jovens sem trabalho, dos desempregados por longo tempo e dos empregados sem seguridade, dos velhos, cujas pensões mal bastam para sobreviver, ou das mães solteiras empobrecidas que dependem de almoços barateados, vale dizer, das cantinas de sopa. Só a política de um legislador que é sensível às pretensões normativas de uma sociedade civil democrática pode converter as pretensões de solidariedade dos marginalizados e de seus advogados em direitos sociais ${ }^{45}$.

O projeto cosmopolita habermasiano de integração democrática dos global players, a fim de criar uma sociedade global socialmente justa tem dois aspectos que devem ser ressaltados: primeiramente, trata-se de uma perspectiva normativa no sentido de que, se queremos pensar em um mundo no qual a política possa contrapor-se à economia, esse passo deve ser dado; em segundo lugar, apresenta uma "perspectiva diacrônica" que conta com a possibilidade do estabelecimento dessa política mundial em múltiplos níveis, com seus diferentes tipos de legitimação, criarem uma espécie de círculo virtuoso para o fortalecimento das decisões em prol da construção de uma ordem mundial mais justa ao longo do tempo, quiçá de uma cultura política de solidariedade e de respeito à democracia e aos direitos humanos. Feitas essas considerações, é possível retornar às críticas apresentadas anteriormente e avaliar em que medida o projeto habermasiano está de fato vulnerável aos problemas apontados.

Mesmo após Habermas enfatizar a necessidade de fortalecer a democracia no âmbito transnacional como um meio para a construção de um projeto político mais inclusivo e menos vulnerável a decisões cujo foco está mais nos interesses do capital do que da justiça social, críticos

45 HABERMAS, 2014, op. cit., p. 145-146. 
como Streeck têm ressaltado que o inimigo habermasiano é mais a tecnocracia do que o capitalismo. Em seu entendimento, Habermas não leva devidamente a sério o conflito de interesses de classes ainda patente nas injustiças globais. A princípio, essa crítica parece um tanto quanto injusta, pois a proposta habermasiana busca enfrentar o capitalismo justamente substituindo a tecnocracia por instituições mais democráticas, nas quais os sujeitos desses conflitos poderiam ter espaço para construir uma sociedade mais inclusiva. Assim, talvez o problema não seja o fim do projeto cosmopolita habermasiano (fortalecer as instituições políticas transnacionais de modo que elas possam contrapor-se ao capitalismo), mas os meios escolhidos para realizar essa finalidade ${ }^{46}$.

Com relação aos meios escolhidos, é relevante problematizar a tese de Habermas de "uma política mundial sem governo mundial" (ou a ideia de Constituição sem Estado) e retomar a questão do déficit democrático. A proposta habermasiana, seja no nível global, seja no nível transnacional, não deixa claro qual a natureza das entidades criadas (não se trataria de um estado ou república mundial no nível global, nem de uma espécie de "federação" no nível transnacional). Contudo, espera-se que essas entidades não estatais desempenhem funções clássicas de Estado, como, por exemplo, uma ONU com poderes coercitivos fortalecidos, ou um bloco regional capaz de imposição da justiça social aos atores econômicos. Nesse sentido, parece que a proposta precisaria de uma legitimação democrática mais forte do que Habermas está disposto a aceitar para os níveis global e transnacional.

Pode-se sustentar, claro, que a proposta de Habermas segue na esteira de uma "utopia realista", segundo a qual o enfraquecimento dos espaços institucionais da legitimação democrática atuaria justamente para tornar a existência desses espaços possível. Contudo, novamente aqui parece que a dimensão mais radical dos conflitos sociais não é abarcada.

46 STREECK, Wolfgang. What about capitalism? Jürgen Habemas'a project of a European democracy. European Political Science, v. 16, n. 2, p. 246-253, 2016. 
O realismo talvez demandasse justamente mais espaço de legitimação democrática ao invés de menos.

Habermas sustenta que a criação de tribunais internacionais no âmbito global pode ser vista como um aspecto racionalizador e civilizador no âmbito de um direito cosmopolita. Como ressaltado por Mouffe (e não apenas em relação ao cosmopolitismo habermasiano), uma das apostas dos defensores do direito cosmopolita é o fortalecimento de instituições judiciais internacionais a fim de afirmar o primado da lei sobre o exercício da força. No entendimento de Mouffe, os diversos modelos cosmopolitas, ao colocarem a ênfase na juridificação das relações internacionais, não levam devidamente a sério os conflitos de interesses existentes nessas relações e, por essa razão, despolitizam a política internacional. ${ }^{47}$

A questão que permanece aberta é se o modelo cosmopolita habermasiano não estaria substituindo uma espécie de tecnocracia (a de um poder executivo como aquele do Conselho Europeu) por outra (a tecnocracia judicial), também permeável aos imperativos do mercado, justamente como se tem visto ocorrer dentro dos Estados nacionais e que tem no Brasil de hoje um exemplo ${ }^{48}$. Assim, o déficit democrático não seria necessariamente um déficit institucional em geral, haja vista que Habermas tem pensado em instituições transnacionais e, notadamente, em instituições judiciais transnacionais. Mas, seria sim um déficit de instituições democráticas abertas à participação e ao controle popular. $\mathrm{Ou}$, ainda, um déficit político, no sentido atribuído por Mouffe ao político como o espaço de poder, de conflito e de antagonismos, que somente podem ser temporariamente acomodados por meio de instituições que sirvam como canais para sua expressão.

\footnotetext{
47 MOUFFE, Chantal. Sobre o político. Trad. Fernando Santos. São Paulo: WMF Martins Fontes, 2015. p. 89-117.

48 Sobre a atuação de cortes constitucionais na defesa de interesses patrimoniais e interesses do mercado em detrimento de outros direitos individuais, Cf. HIRSCHL, Ran. Towards Juristocracy: the origins and consequences of the new constitutionalism. Cambridge, Massachusetts and London: Harvard University Press, 2007. A respeito deste tema no Brasil. Cf. ANDRADE, Ledio Rosa de. $O$ Superior Tribunal de Justiça e os Ricos: a cartilha neoliberal. Florianópolis: Empório do Direito, 2016.
} 


\section{Referências}

ANDRADE, Ledio Rosa de. O Superior Tribunal de Justiça e os Ricos: a cartilha neoliberal. Florianópolis: Empório do Direito, 2016.

BAYNES, Kenneth. Cosmopolitan Condition. In: BRUNKHORST, Hauke; KREIDE, Regina; LAFONT, Cristina. The Habermas Handbook. New York: Columbia University Press, 2018. p. 541-543. https://doi.org/10.7312/brun16642-051

COHEN, Jean L. The Constitutionalization of International Law. In: BRUNKHORST, Hauke; KREIDE, Regina; LAFONT, Cristina. The Habermas Handbook. New York: Columbia University Press, 2018. p. 143-152. https:// doi.org/10.7312/brun16642-019

HABERMAS, Jürgen. A Constelação Pós-Nacional: ensaios políticos. Trad. Márcio Seligmann-Silva. São Paulo: Littera Mundi, 2001.

HABERMAS, Jürgen. A inclusão do outro: estudos de teoria política. Trad. Georg Sperber e Paulo Astor Soethe. São Paulo: Loyola, 2002.

HABERMAS, Jürgen. O Ocidente dividido: Pequenos escritos políticos $X$. Trad. Bianca Tavolari. São Paulo: Unesp, 2011.

HABERMAS, Jürgen. Sobre a Constituição da Europa: um ensaio. Trad. Denilson Luis Werle, Luiz Repa e Rúrion Melo. São Paulo: Unesp, 2012.

HABERMAS, Jürgen. Na esteira da tecnocracia. Trad. Luiz Repa. São Paulo: Unesp, 2014.

HIRSCHL, Ran. Towards Juristocracy: the origins and consequences of the new constitutionalism. Cambridge, Massachusetts and London: Harvard University Press, 2007. https://doi.org/10.1093/icon/molo20

LAFONT, Cristina. Alternative visions of a new global order: what should cosmopolitans hope for? Ethics \& Global Politics, London, v. 1, n. 1-2, p. 41-60, 2008. https://doi.org/10.3402/egp.v1i1.1813

MOUFFE, Chantal. Sobre o político. Trad. Fernando Santos. São Paulo: WMF Martins Fontes, 2015.

ROELE, Isobel. The Vicious Circles of Habermas' Cosmopolitics. Law Critique, [New York], v. 25, p. 199-229. 2014. https://doi.org/10.1007/s10978-014-9138-4

SCHEUERMAN, William E. All Power to the (State-less?) General Assembly! Constellations, Washington (D.C.), v. 15, n. 4, p. 485-492, 2008. https://doi. org/10.1111/j.1467-8675.2008.00508.x 
SCHEUERMAN, William E. Global Governance without Global Government? Habermas on Postnational Democracy. Political Theory, Thousand Oaks, v. 36 n. 1, p. 133-151, 2008.

STREECK, Wolfgang. Small-State Nostalgia? The Currency Union, Germany, and Europe: A Reply to Jürgen Habermas. Constellations, Washington (D.C.), v. 21, n. 2, p. 213-221, 2014. https://doi.org/10.1111/1467-8675.12083

STREECK, Wolfgang. What about capitalism? Jürgen Habemas'a project of a European democracy. European Political Science, New York, NY, v. 16, n.2, p. 246-253, Jun. 2016. https://doi.org/10.1057/eps.2016.3

\section{Endereço Postal}

Universidade Federal do Paraná. Departamento de Filosofia. Rua Dr. Faivre, 405 - $6^{\circ}$ andar - Ed. D. Pedro II - Curitiba - PR - CEP 80060-140. E-mail: crisforoni@yahoo.com.br 